\title{
LEGIBILITY
}

A major purpose of the Technical Information Center is to provide the broadest dissemination possible of information contained in DOE's Research and Development Reports to business, industry, the academic community, and federal, state and local governments.

Although a small portion of this report is not reproducible, it is being made available to expedite the availability of information on the research discussed herein. 
LA.UR $-89-3395$

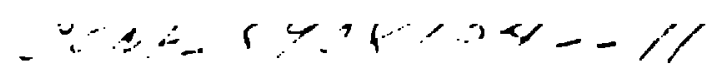

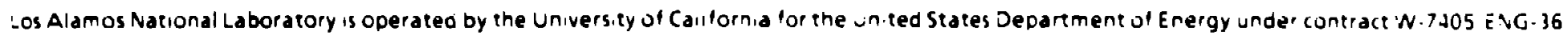

\title{
TITLE: HIGH-FIELD PULSED MICROWIGGLERS
}

$\begin{array}{ll} & \\ \text { AUTHOR(S): } & \text { LA-UR- W. Warren } \\ \text { D. W Feldman } & \text { DE90 } 002388 \\ \text { D. Preston } & \end{array}$

\author{
SUBMITTED TO: Eleventh International Free Electron Laser Conference \\ Naples, Florida \\ August 28-September 1, 1989
}

\section{IMS I.AIMR:R}

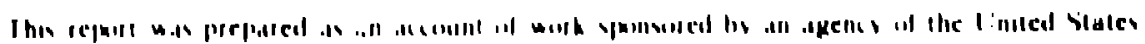

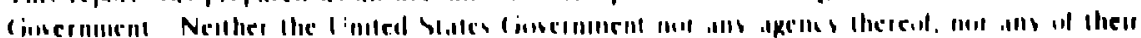

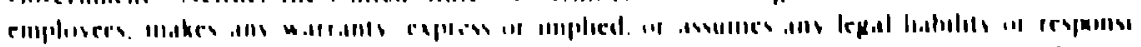

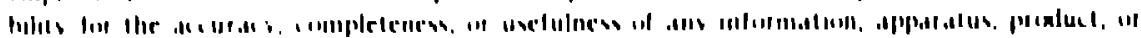

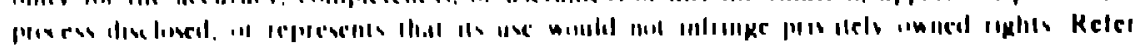

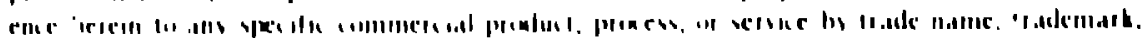

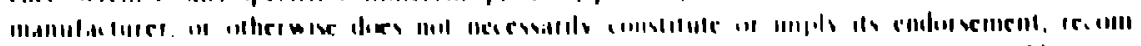

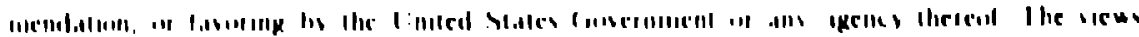
年

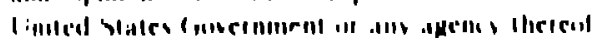

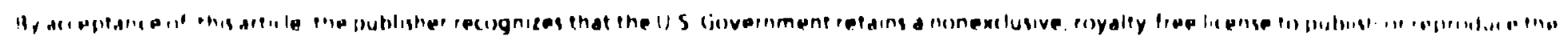

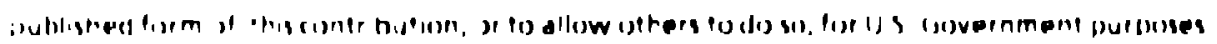

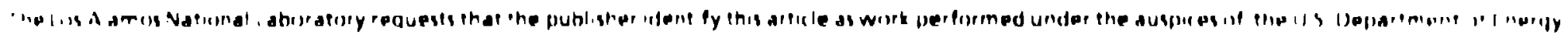

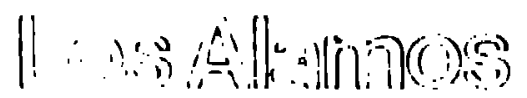

Los Alamos Natir) lat! Laboriltor y Los Alarrio's. New Moxico B375.4', 


\title{
HIGH-FIELD PULSED MICROWIGGLERS*
}

\author{
Roger W. WARREN, Donald W. FELDMAN
}

Los Alumos National Laboratory, Los Alamos, NM $\varepsilon 7545$

Telephone (505) 607-1088. FAX (505) 607.0910

Daryl PRESTON

California State University, Hayuard. CA 94542

\begin{abstract}
Conventiond wigglers made with periods of less than a few centineters gemernte light of short wavelength, but usually have low gnin berause of their low fields. Iron-free clecetromagnets driven by high pulsed currents can kenerate the high fields needed. We will discuss the design and construction of such magnets.
\end{abstract}

\section{Introduction}

There has recently been considerable interest [1] in bulding microwigglers, i.e., wig. glers with periods signiticnutly shorter than one centimeter, bechuse of their proposed use to genernte light of short wavelength with electron benus of only modernte enerky.

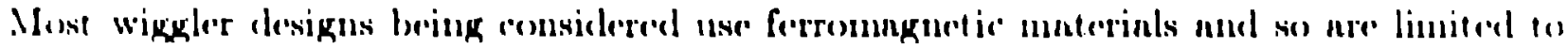
it muximum field at the manguets of 1 to 2 T und lower fields on the wiggler's "xis. A

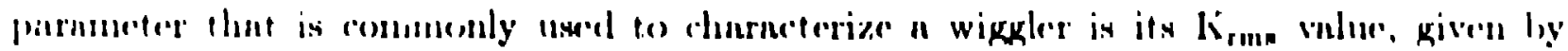

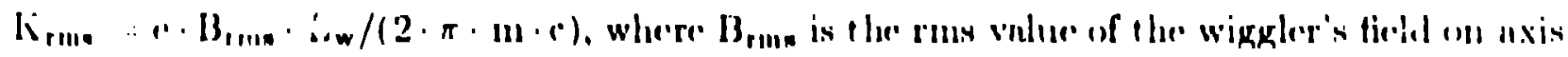

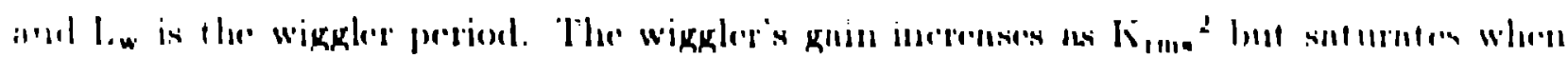

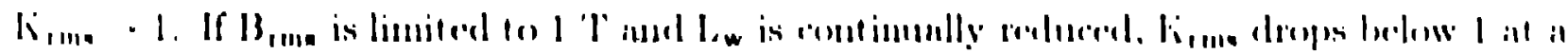

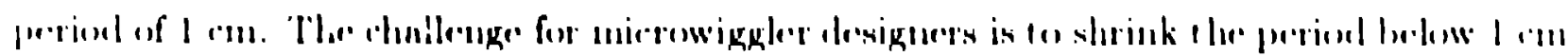

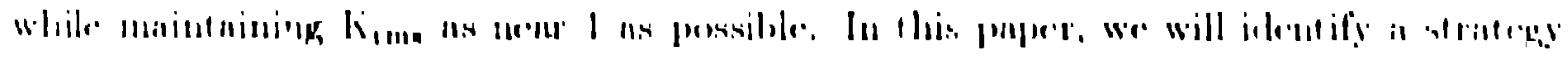

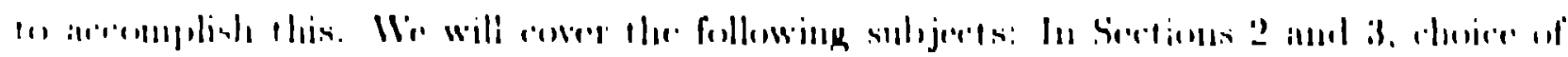

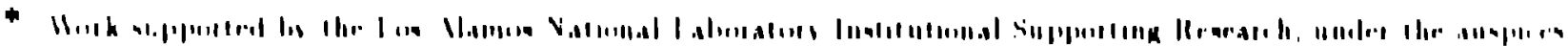

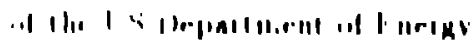


designs for microwigghers and estimntes of the expected performance of the best designi in Section 4, the wigglers that we have built: in Section 5 . the performanee of these wigghers ind the problems encountered: finally: in Sertion 6. conclusions.

\section{2. nesign :hoices}

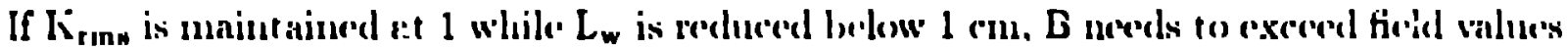
that can be produced we ferromagnetic materiols. Thus, we must eliminate such materials from the wiggler. Supercouductors. look nttractive as conducturs but, at the present time. (amust support current densitios in excess of $10^{4} \mathrm{~A} / \mathrm{sg}$ cm. Estimates show that densities

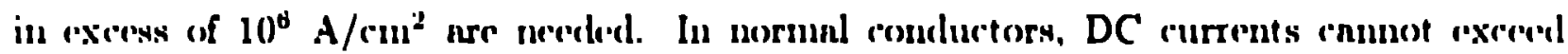
densities of about $10^{3} \mathrm{~A} / \mathrm{rm}^{2}$ without excessive henting. Enoly experiments [2] show that current alensities of the repuired magnitude con be genernted by pulsed currents in copper roils. Pulsed currents in some constigurntion of copper-like conductors ure, therefore, the" busis of this work.

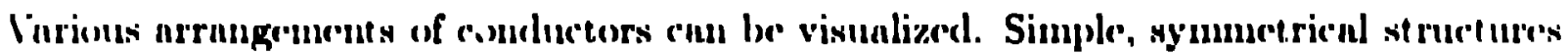

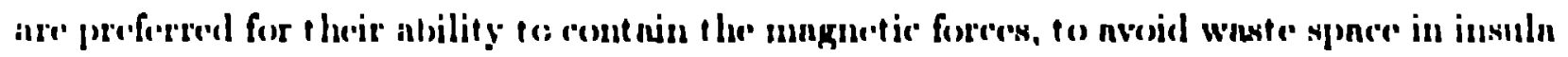
tion. mul to nvoid nreing nt erossovers. The simplest wiggher sut infying these conditions and

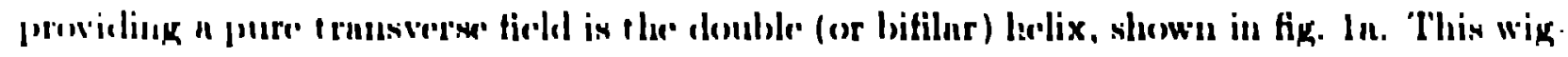

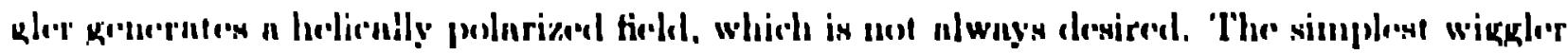

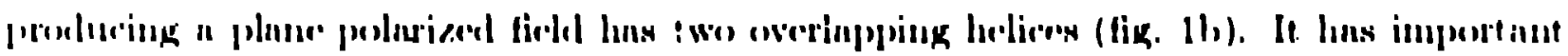

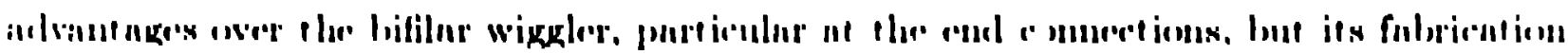

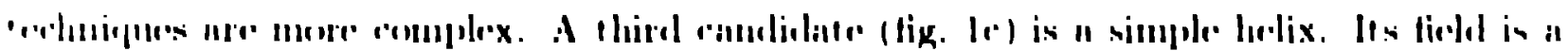

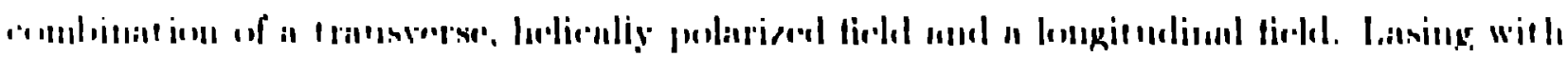

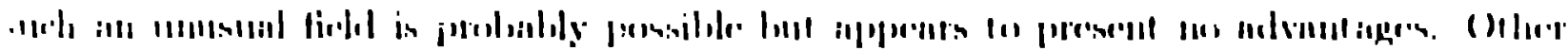

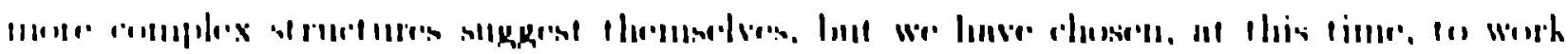

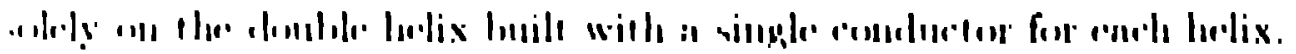

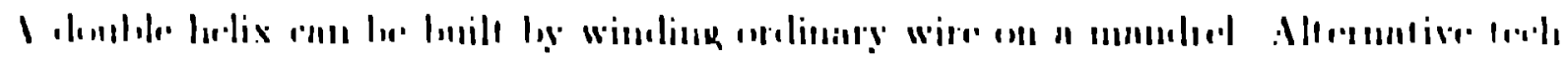

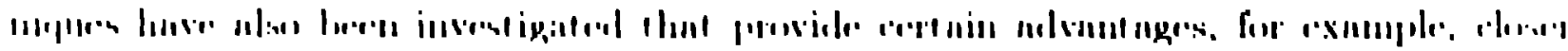


tolerances, higher fields, or better cooling. A major problem with these techniques, howcver. is providing electrical contacts at the ends. A wound conductor automatically satisfies this need and, therefore, has been picked as our primary dhoice. Wound condenctors can be round or have a rectangular or semicircular cross section that generates a higher field. A hollow conductor provides a passage for a coolant. We have, so far. chosien to work only with round, solirl, or tubular copper conductors that are wound on an insulatec., hollow nuetal tube. using a lathe and suitable wire feeders to maintnin rlose tolerances on the period. Wi ne certainly not the first investigators to work with a wound bifilar le lix. What distinguishes our work is our emphasis on a $K_{\text {rms }}$ value of 1 and our at tempt to push rechuology to its limits to reach small values of period.

\section{Estimates of performance}

In estimuting the performance of a double helix wiggler, we have chosen parameters to mimic the Los Alamos 1-m unt npered wiggier. The ratio of period to gap, for example, is $\pi$. With this ratio, the conductors are wound at $845^{\circ}$ angle with respect to the axis. We have picked the conductors to be single strands of round eopper wire with a diameter surh that

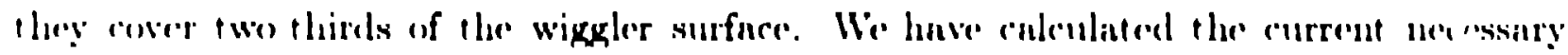

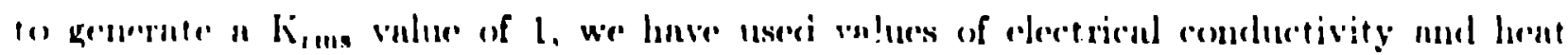

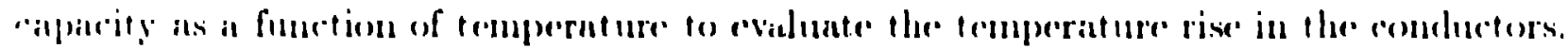

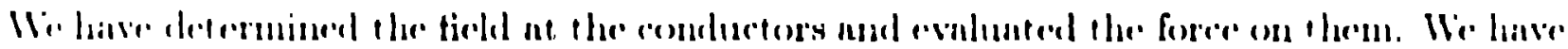

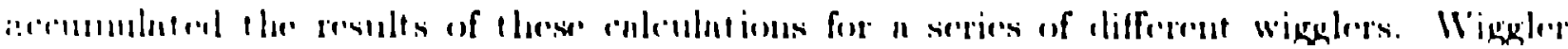

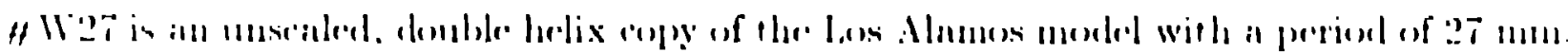

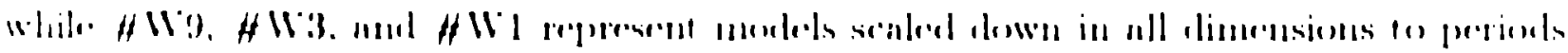

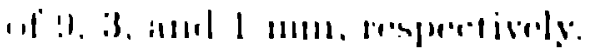

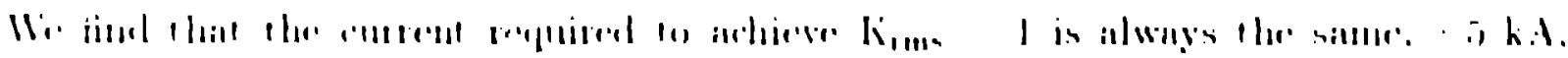

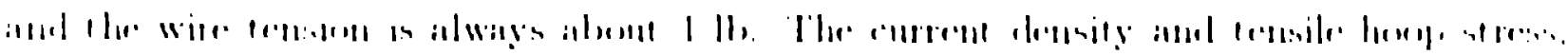

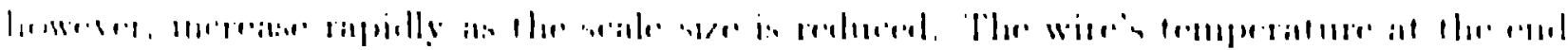

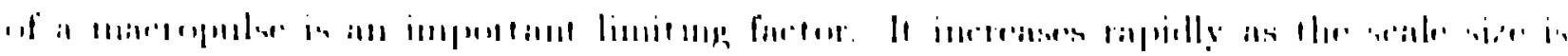


reduced and the macropulse is lengthened. We have chosen to use a 100 -ph pulse beciltse this is the planned pulse length of the FEL at Los Alanos. Pulse times as short as 1 to $10 \mu \mathrm{s}$ might be used, however, if the small-signal gain is large enough and the optical cavity short enough so that saturation is reached in this time. We have not scaled to sizes smaller than \#Wi because the wire's temperature would exced its melting point after $100 \mu \mathrm{s}$.

Auther limiring factor is the breat.ing stress of the conductor. For copper conductors used with a $100-\mu$ s pulse, the temperature limit cocurs first. For a shorter pulse. the breaking limit comes first. Both limits can be relaxed by various means, e.g. supporting the wire or cooling the conductor. Supporting the wire is an casy and successful fix. Immersing a conductor in a cool Huid is not usually effective in extracting hent from the conductor cluring the short heat pulse, but provides us with a lower starting temperature (allowing a longer macropulse) and provides better cooling between macropulses (allowing a higher pulse repetition rate). We have made estimates of the gains to be made in macropulse length by cooling to liguid nitrogen, hydrogen, or helium temperntures and find increases by factors of about 2, 4, and 8, respoctively. These improvements may not be realized in practice herouse we have assumed idend behavior of the conductors. i.e.. perfect purity no strin, me magnetoresist dunce, ete. Comparison has beren ande of the

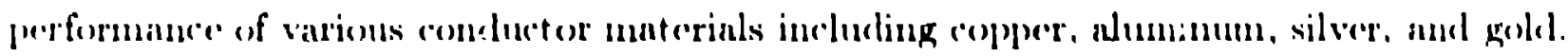
Copper preforms as well or better then the others and is incxpension, ensy to work with.

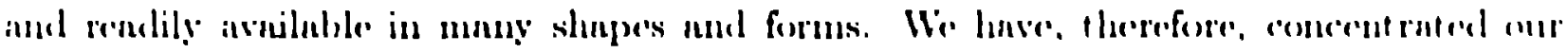
Affinsts on copper.

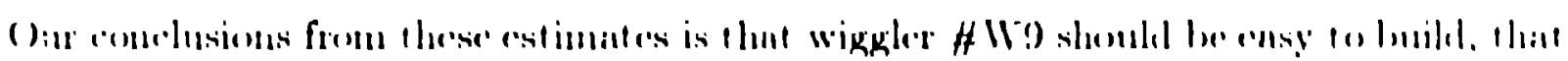

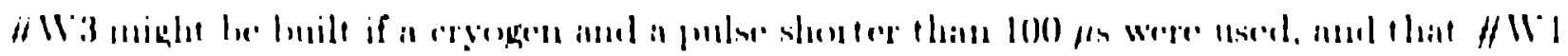

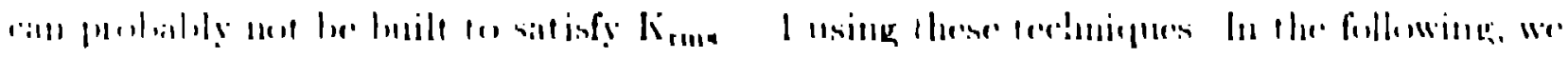

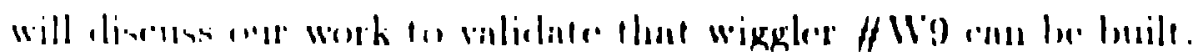




\section{Hardware}

Wi. have built an apparatus to test conductors with current pulse's up to about 30 hit in a clamped sine-wave format with a hadf period of $150 \mu \mathrm{s}$. With this device, we tested the range of currents that different copper wires could tolernte before exploding. The result: were in fair agrement with the calculated linit corresponding to the melting point of copper. This same apparatus was used in many tests with compiete' wigglers. 'The firs! wigglers that we built were wound of solid \#16 copper wire $(1 \mathrm{~mm}$ dian! covered wit 1 fibcrglas.i-epoxy. The repertition rate for a $100-\mu$ s pulse must t-e less than $1 /$ min to avoid overheating. The next wigglers were wound of copper tulsing covered with fiberglass-epoxy: The repetition rate could then be raised to about $1 / 5$ because of the internal cooling afforcled. Designs have been mornced to further improve heat removal hy providing mnny shert, parallel paths for coolant How between adjacent wires. Do models heve yet been built following these clesigns. If special care is not taken with the desipn of the ends of a wiggler, the fields generated there cause a net bend to the electron beam. This chn be (asily cont rolled by making the two windings of the donble helix identical. One con show that the ands then genernte no nngular error and ouiy a small offset tos an ilactron besun in the bosly of the wiggler. 'Tn preserve this symmetry, the conductor lends at both

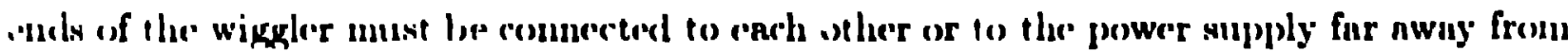

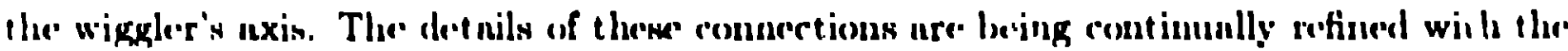

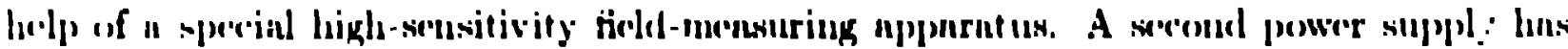

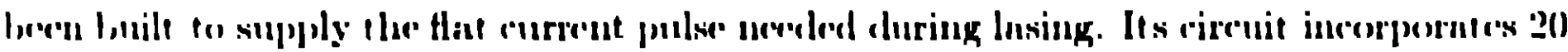

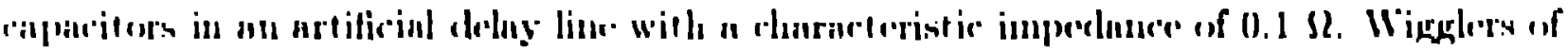

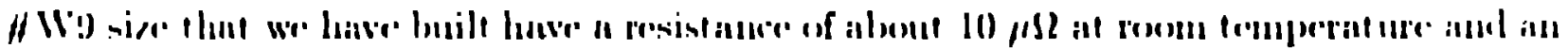

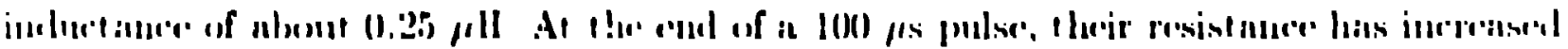

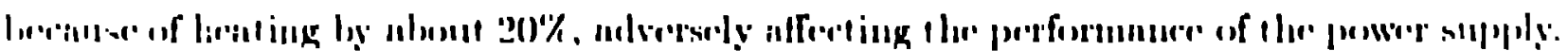

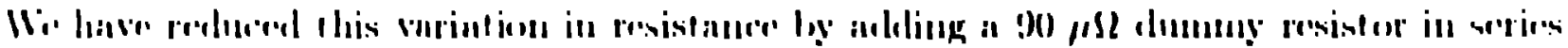

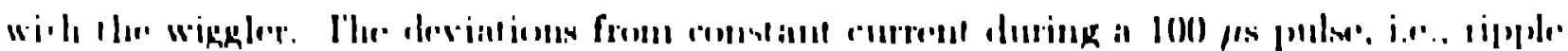


and slump. are then less than 2\%. Modifications to the design of the power supply are being made to improve this performance by employing artive feedback.

\section{Performance of models of \#W9 Built}

Fig. 2 shows a wiggler made with copper tubing being wound by a lathe on an insulated stainless steel hypodermic mandrel of $2.9 \mathrm{mmn}$ o.d. and $2.2 \mathrm{~mm}$ i.d. This wiggler hiss 25 wiggles with a period of $8.5 \mathrm{~mm}$ : the copper tube has an o.d. of $2.1 \mathrm{~mm}$ and $\mathrm{nm}$ i.d. of $0.8 \mathrm{~mm}$; the insulating layer is $0.1 \mathrm{~mm}$ thick. When finished, the wincling will be covered with fiberglass impregnated with epoxy. Fig. 3 shows a partially conupleted wiggler mounted between vacuum Hanges and connected to a coaxial-cable current source and to coolant tubes. The outer aluminum shield has been removed for the pirture. Models like this are checked for electrical integrity, feld uniformity, and end effects with a pulsed-wire field-measuring setup. This mensuring technique has been discussed in the literat ure $[3, i]$. When npplied to pulsed wigglers, this technique works without new problems and presents sereral new udvantages over alternative field measuring techniques: The "field probse" is a 1- to 2-mil tungsten wire thrended down the hypodermic tube. Clenrly. very small wigglers can be measured with surh a prober. Seromd, this technigue uses a rurrent pulser a few microsectonds iong passing through the tungsten wire. By changing the piming of the pulse', fiolds generated at different times in the macropulse cou lee investignted. Finnlly, the short current pulse generates a transverse deflection of the wire that propagntes to the

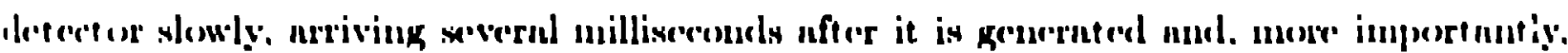

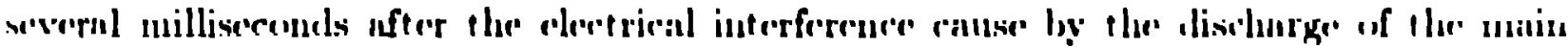

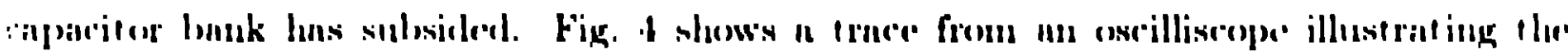

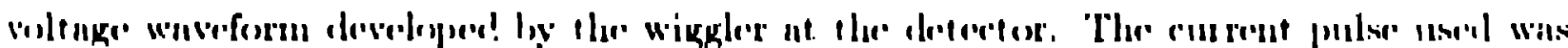

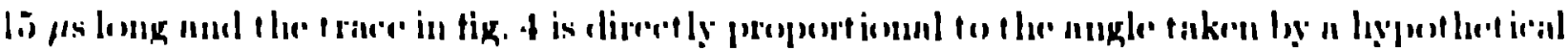

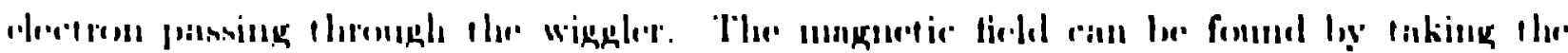

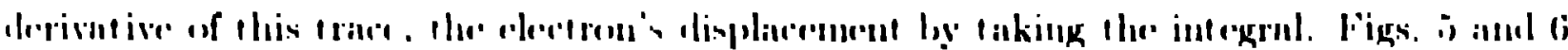

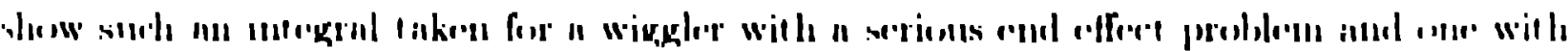


a problem that is small because of its symmetrical construction. Fig. $i$ is a photo showing this field-measuring technique in use with a typical wiggler.

In addition to problems at the ends of a wiggler, one can detect nonsinusoidal displacements of the electron at other places in Figs. 5 and 6. These are caused by irregularities in the windings resulting from nonuniformities in the mandrel, the insulation, the tubing. or its positioning. The extraneous displacements are not significant as long as they remain small compared to the magnitude of the sinusoidal displacements. Such is the case for the examples shown. We expect to reduce these aberrations as we gain a better understancling of the winding technique.

\section{Conclusions}

Several models of a 9-mun-period pulsed wiggler have been built and tested. They casily produce a $K_{\mathrm{rm}}$ value of 1 and have acceptable field uniformity and end effects. Being built with a hollow conductor, they can be used with a pulse repetition rate of $1 / \mathrm{s}$ or so. The wigglers are housed in an assembly that provides convenient vacuum, electrical, and coolant connections, minimizes wakefields, and shields the wiggler and the ambient from cach other. A power supply to provide the flat current pulse that is reduired has ben completed and is indergoing tests.

Bissed on the experience gnined with wigglers of this size, smuller morlely npperar to loe buildable, but modified slesigns such as the erossed-helix ronfigurntion and modified

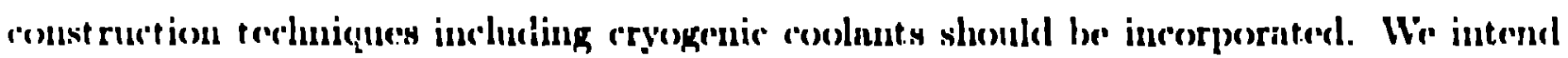
fo purster these appronelues.

\section{Arknow ledgunents}

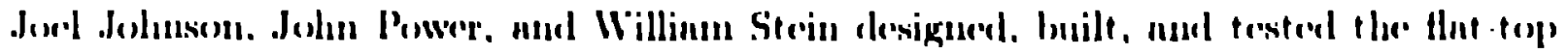

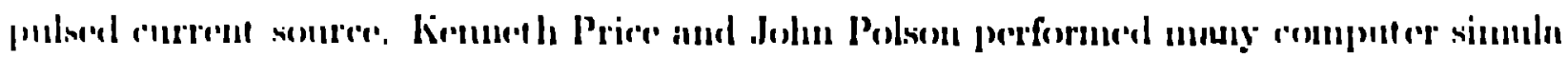

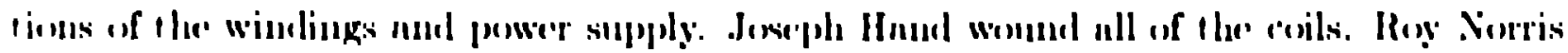

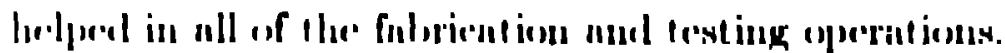




\section{References}

[1] Richard L. Sheffield, Jerry M. Watson, Bruce E. Carlsten, and John C. Goldstein, "Workshop Results On Small-Period Wiggler Designs," this conference (paper U.N.1).

[2] R. IV. DeBlois, "Miniature Coils for High Magnetic Field Research," RSI 32, S16 (1061).

(3) R. W. Warren and C. J. Elliott. "New System for Wiggler Fabrication and Testing." Proc. Adriatiro Res. Conf. on Undulator Magnets for Synchrotron Radiation and Free-Electron Lasers, Eds. R. Bonifacio, L. Fonda, and C. Pelligrini, World Scientific. Singapore, 1938.

[t] R. W. Warren, "Limitations on the L'se of the Pulsed-Wire Field Measuring Technique." Nucl. Inst. and Meth. in Phys. Res. A 272, 257 (1088).

\section{Figure Captions}

Fig. 1a. A bifilar 'selix.

Fig. 1b. A crossed double helix.

Fig. 1r. A simple helix.

Fig. 2. Bifilar hrlix being wound.

Fig. 3. Completed wiggler assembly.

Fig. 4. Signal from pulsed-wire system.

Fig. 5. Integral showng deflection for bad wiggler.

Fig. 6. Integrol for goosd wiggler.

Fix. 7 . Field mensuring setup, showing the fixture's used to terst the effects of a nearly Hange, londs in the wikgler. nud different end connortions. 


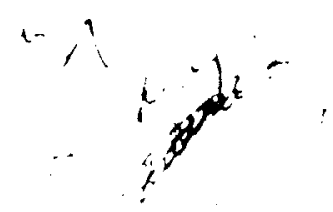

$39 \cdots 343$
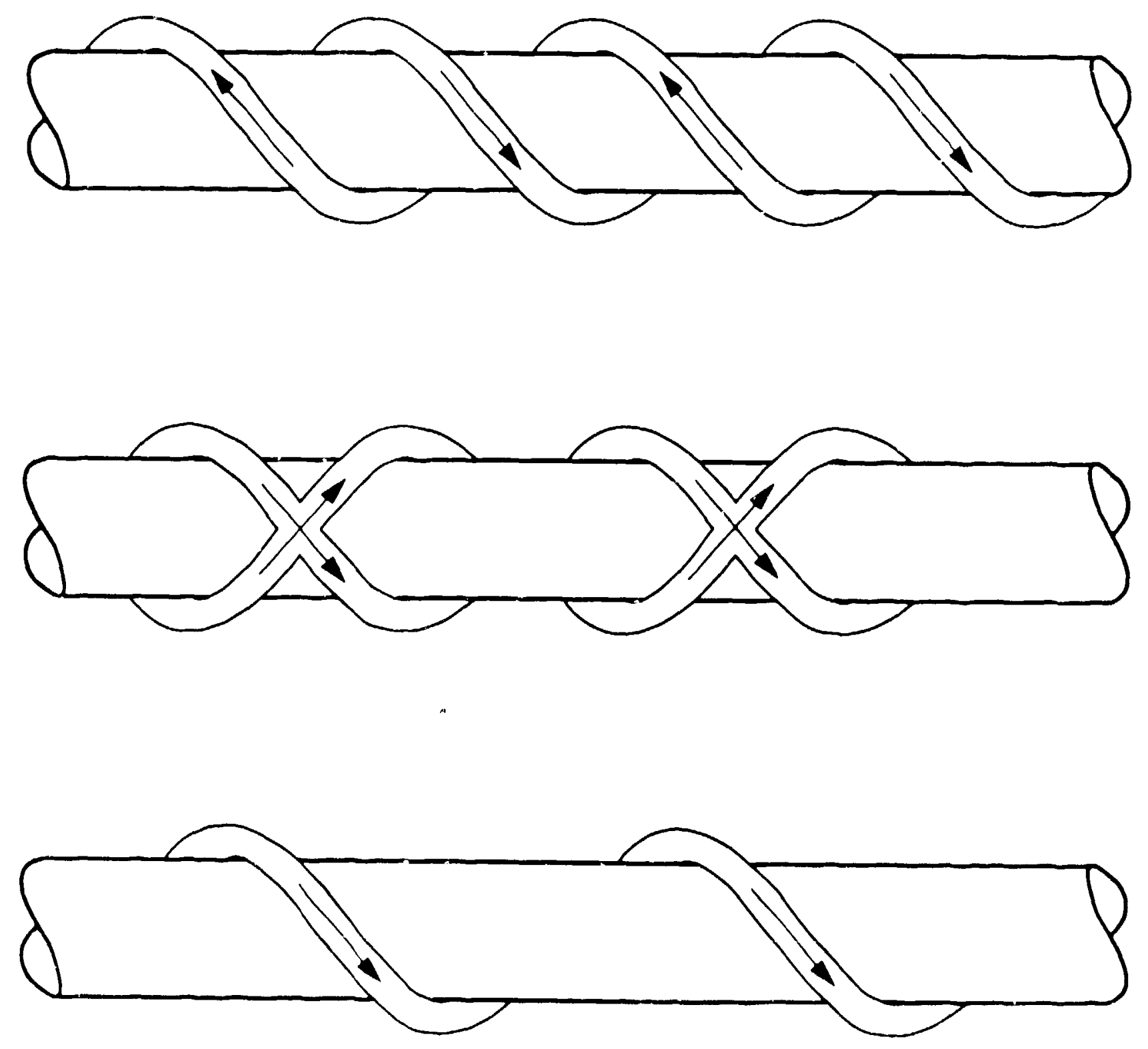


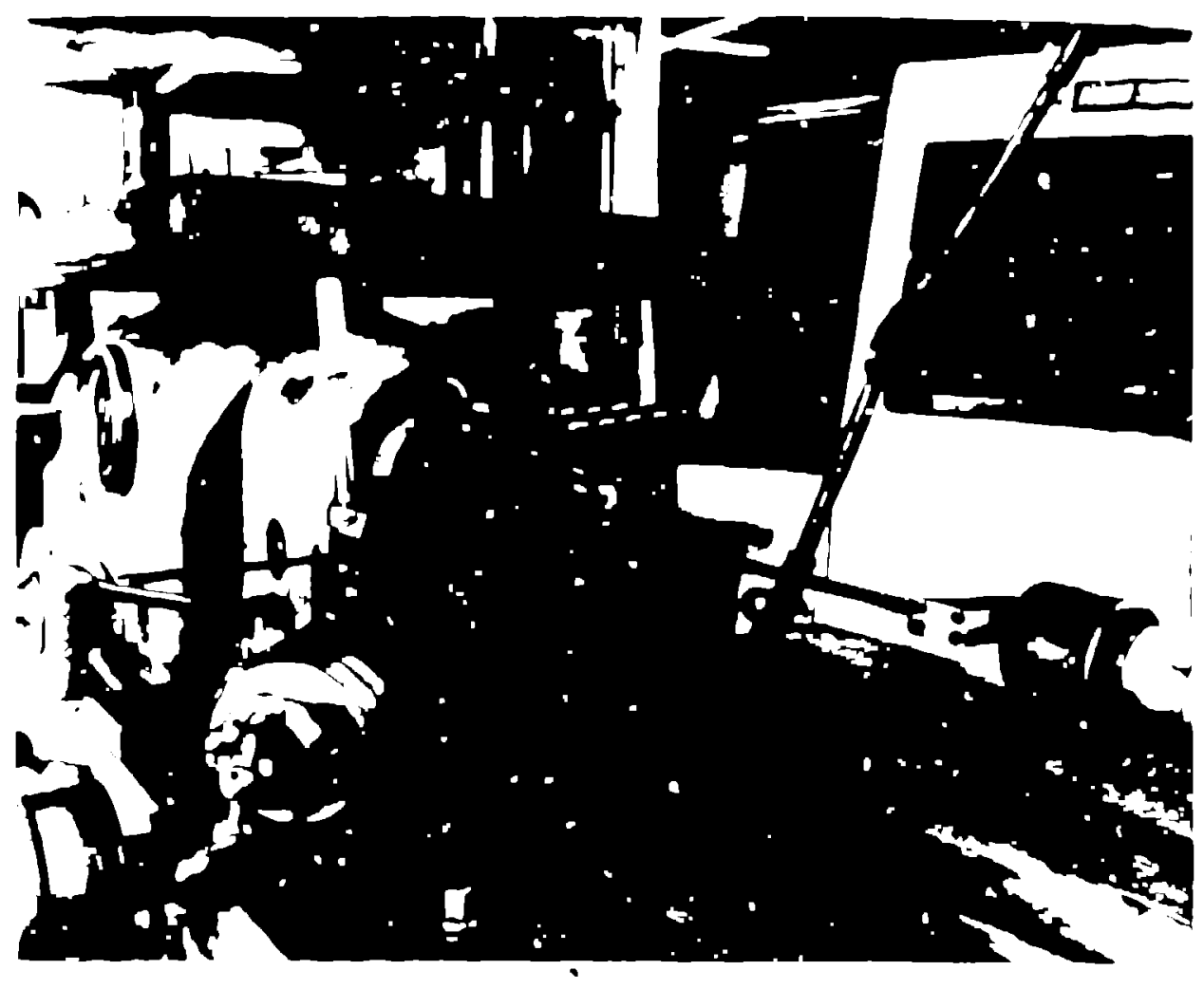

REPRODICED FROM BEST AVAILABLE COPY 


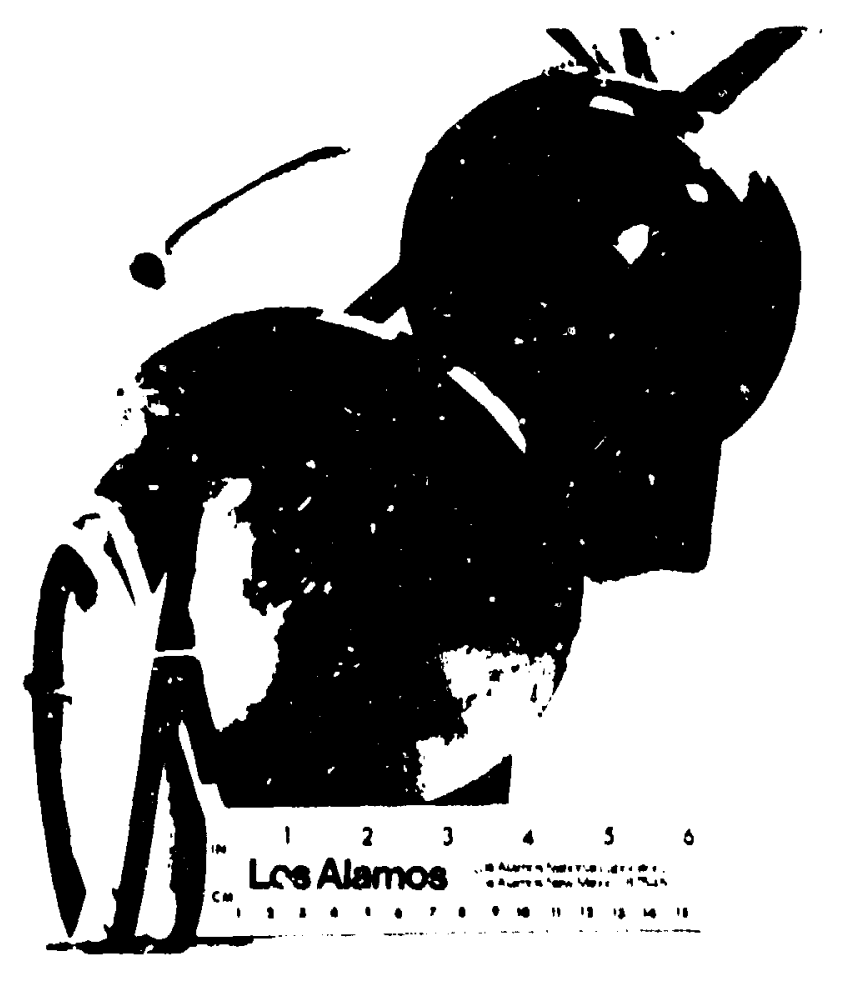

Fys

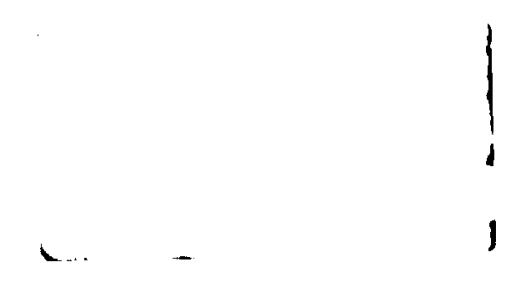




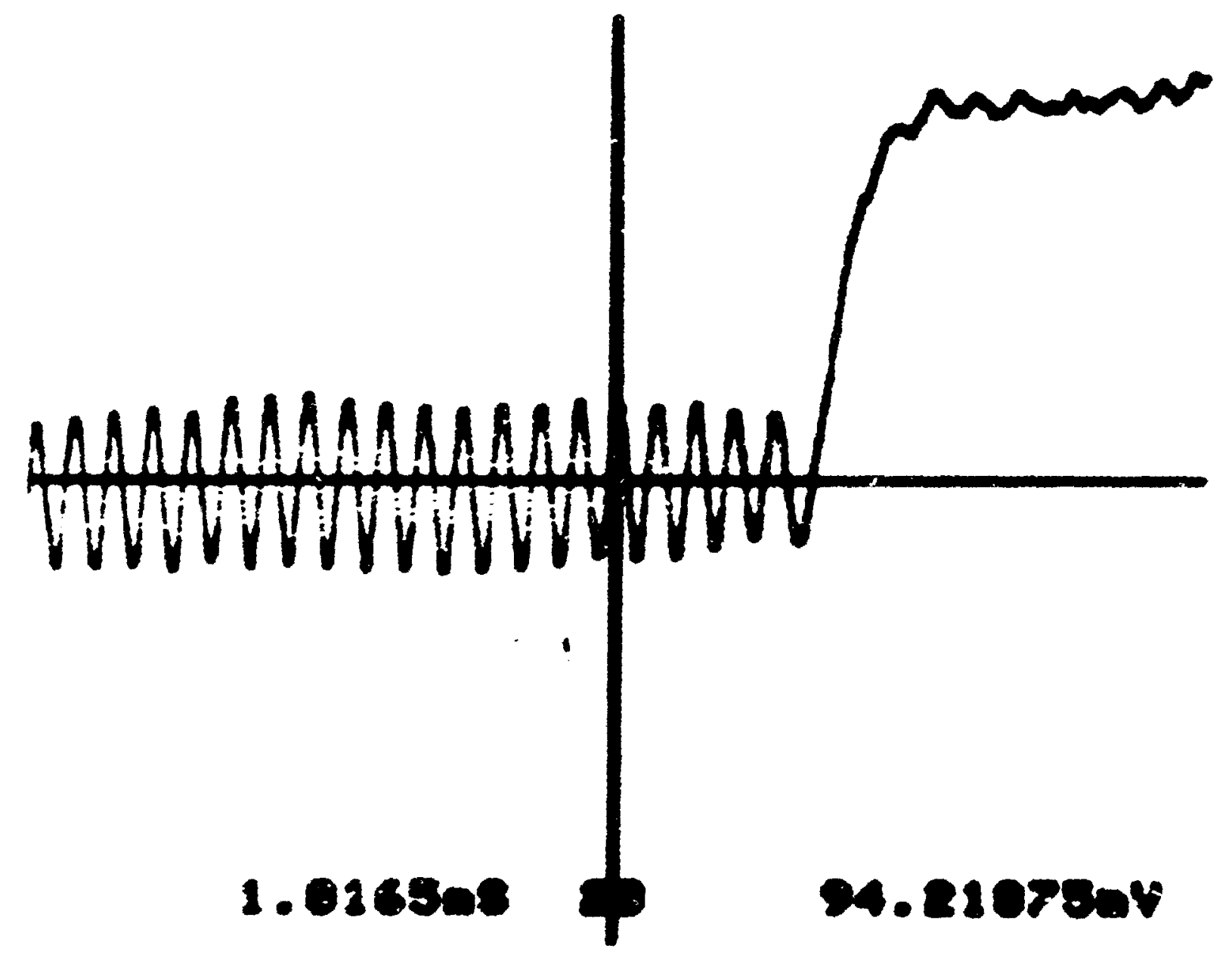

REPRODUCED FROM BEST

AVAILABLE COPY 


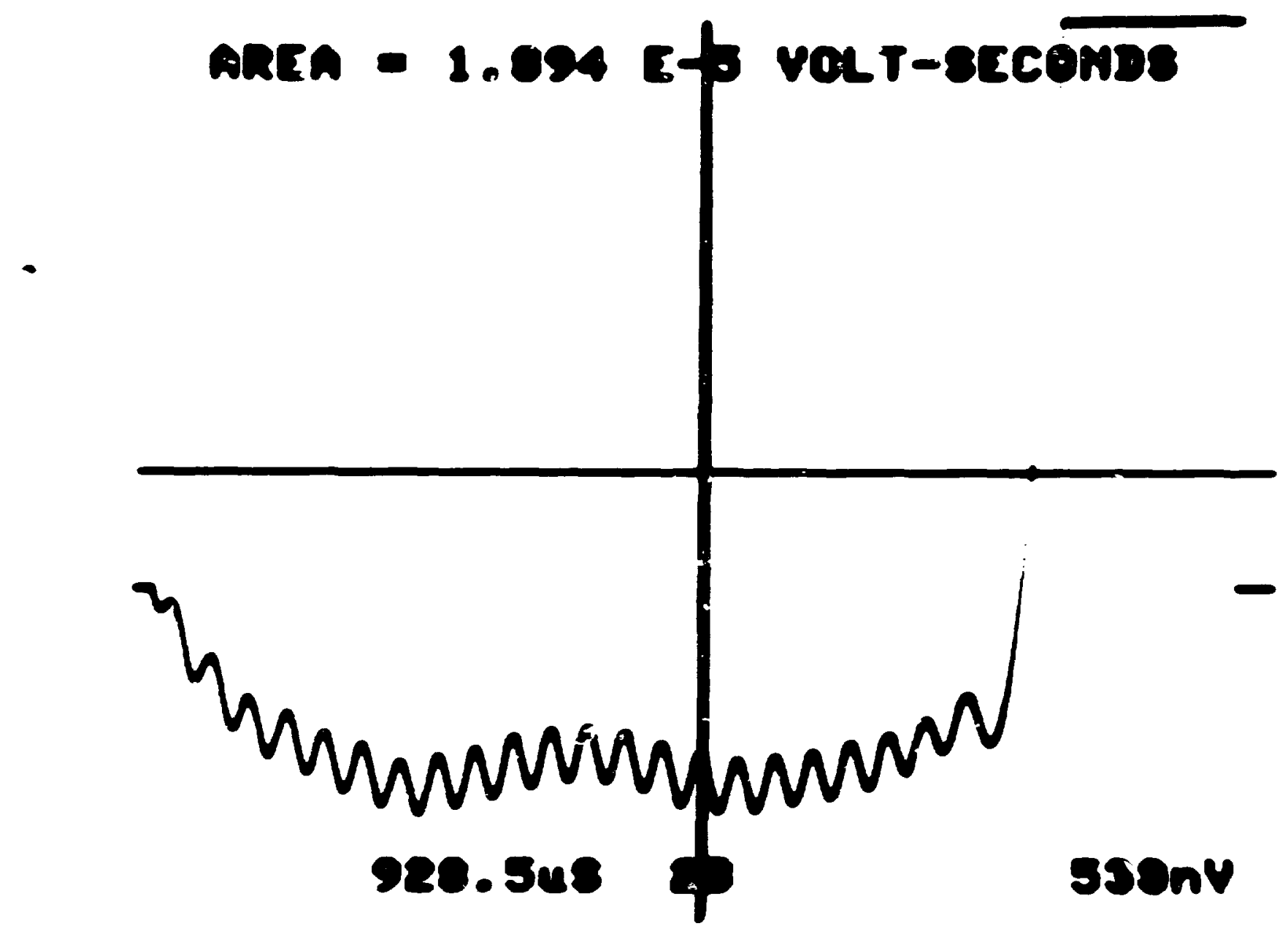

REPRODUCED FROM BEST AVAILABLE COPY 


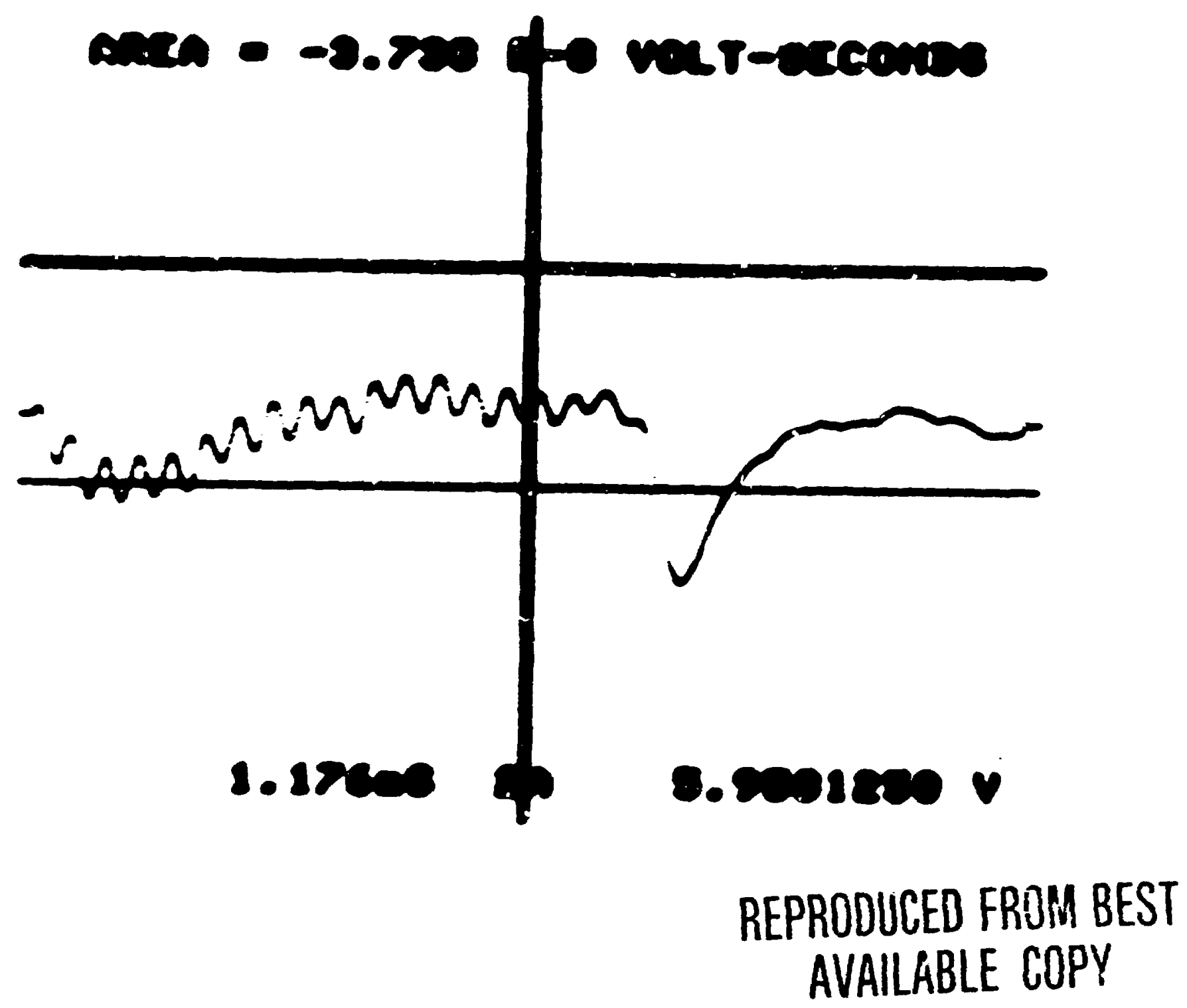




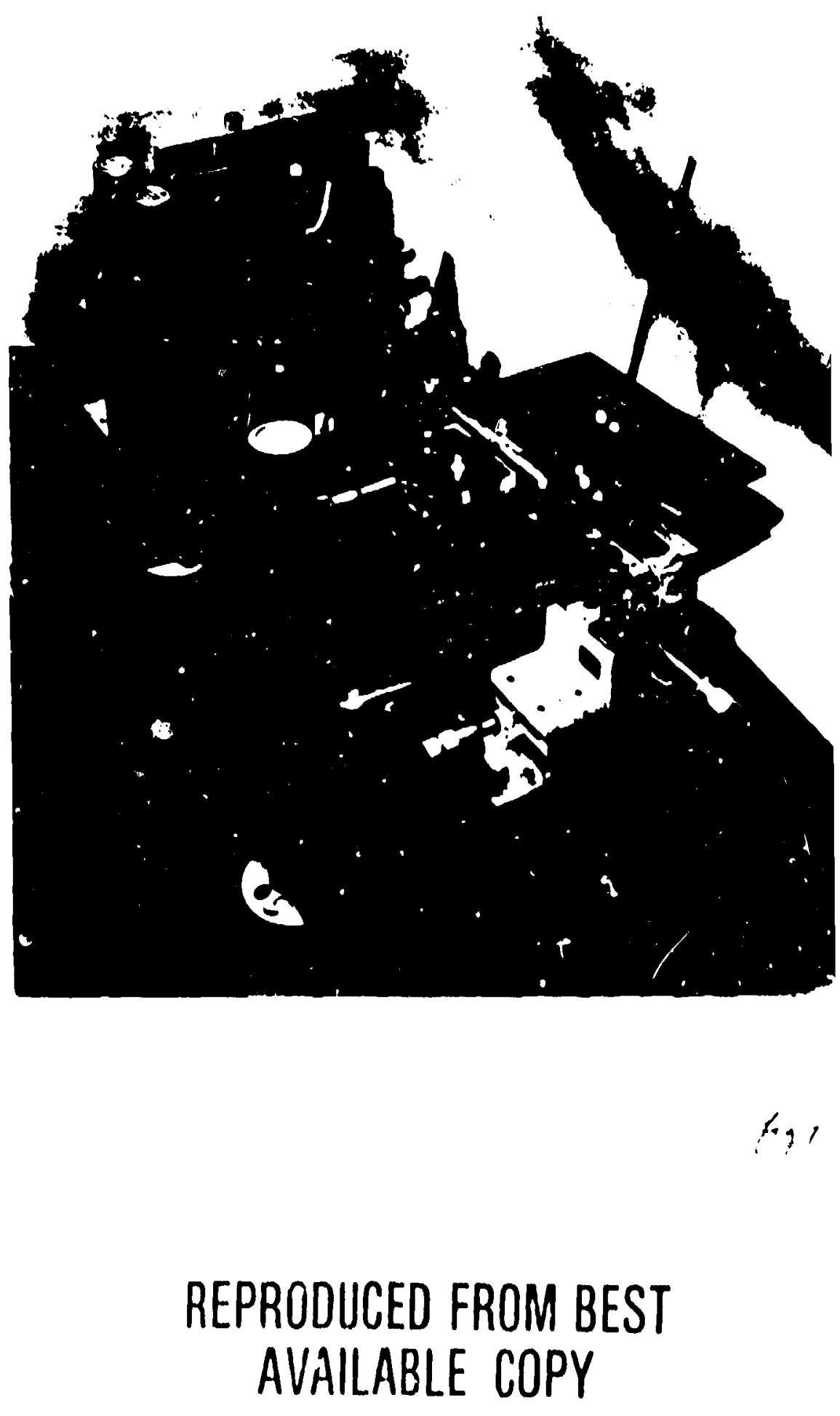

